Check for updates

Cite this: Chem. Commun., 2019, 55, 3556

Received 7th February 2019, Accepted 27th February 2019

DOI: 10.1039/c9cc01113g

rsc.li/chemcomm

\section{A facile preparation of functional cycloalkynes via an azide-to-cycloalkyne switching approach $\dagger$}

\author{
Suguru Yoshida, (D)*a Tomoko Kuribara, ${ }^{a}$ Harumi Ito, (D) ab Tomohiro Meguro, ${ }^{a}$ \\ Yoshitake Nishiyama, ${ }^{a}$ Fumika Karaki, ID $\ddagger^{\mathrm{a}}$ Yasutomo Hatakeyama, ${ }^{\mathrm{C}}$ Yuka Koike, ${ }^{\mathrm{C}}$ \\ Isao Kii iD bc and Takamitsu Hosoya (D) *ad
}

A facile method for preparing various functional cycloalkynes, including proteins incorporated with a cycloalkyne moiety, from the corresponding azides is developed. Treatment of diynes bearing strained and terminal alkyne moieties with a copper salt enabled terminal alkyne-selective click conjugation with azides, whereas a more azidophilic strained alkyne moiety was transiently protected from the click reaction via complexation with copper.

Copper(I)-catalyzed azide-alkyne cycloaddition $(\mathrm{CuAAC})^{1}$ and strain-promoted azide-alkyne cycloaddition (SPAAC) ${ }^{2,3}$ are trailblazing reactions of click chemistry ${ }^{4-6}$ widely used to reliably conjugate molecules in various disciplines, including materials chemistry, ${ }^{7}$ pharmaceutical sciences, ${ }^{8}$ and chemical biology.${ }^{9}$ In particular, SPAAC is one of the most convenient methods widely applied to functionalize a broad range of molecules. This popularity stems from its applicability even in the presence of complex mixtures of molecules such as biological samples. However, preparation of cycloalkynes bearing a functional moiety is often troublesome because of the high reactivity of strained alkyne moieties and the limited number of available conjugation methods that depend on the functional moiety.

To render various cycloalkynes more easily synthesizable, we previously developed a transient protection method for

\footnotetext{
${ }^{a}$ Laboratory of Chemical Bioscience, Institute of Biomaterials and Bioengineering, Tokyo Medical and Dental University (TMDU), 2-3-10 Kanda-Surugadai,

Chiyoda-ku, Tokyo 101-0062, Japan. E-mail: s-yoshida.cb@tmd.ac.jp, thosoya.cb@tmd.ac.jp

${ }^{b}$ Laboratory for Pathophysiological and Health Science, RIKEN Center for Biosystems Dynamics Research (BDR), 6-7-3 Minatojima-minamimachi, Chuo-ku, Kobe 650-0047, Japan

${ }^{c}$ Common Facilities Unit, Compass to Healthy Life Research Complex Program, RIKEN Cluster for Science, Technology and Innovation Hub, 6-7-3 Minatojima-minamimachi, Chuo-ku, Kobe 650-0047, Japan

${ }^{d}$ Laboratory for Chemical Biology, RIKEN Center for Biosystems Dynamics Research (BDR), 6-7-3 Minatojima-minamimachi, Chuo-ku, Kobe 650-0047, Japan

$\dagger$ Electronic supplementary information (ESI) available: Experimental procedures and characterization of new compounds including NMR spectra. See DOI: 10.1039/c9cc01113g

\# Present address: Laboratory of Medicinal Chemistry, School of Pharmacy, Kitasato University, 5-9-1 Shirokane, Minato-ku, Tokyo 108-8641, Japan.
}

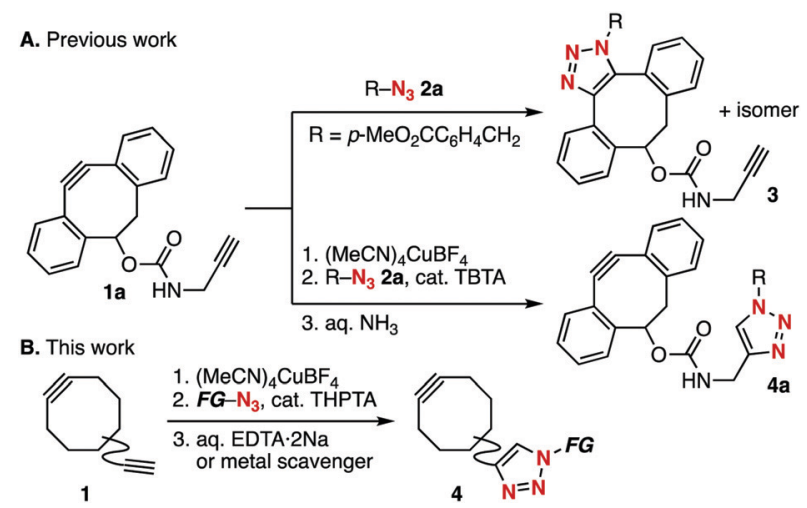

Fig. 1 Selective click reactions of diynes bearing strained and terminal alkyne moieties. TBTA $=\operatorname{tris}((1-$ benzyl-1H-1,2,3-triazol-4-yl)methyl)amine and THPTA = tris((1-(3-hydroxypropyl)-1H-1,2,3-triazol-4-yl)methyl)amine. $F G=$ functional group.

cyclooctynes (Fig. 1).$^{5 h}$ Normally, the reaction of dibenzo-fused cyclooctyne 1a bearing a terminal alkyne moiety with azide $\mathbf{2 a}$ proceeds exclusively towards the more azidophilic strained alkyne moiety to afford SPAAC product 3 (Fig. 1A). We found that pre-treatment of diyne 1a with a cationic copper salt resulted in the formation of a cyclooctyne-copper complex, which enabled selective CuAAC conjugation at the terminal alkyne moiety. Removal of the copper salt from the complex using aqueous ammonia afforded cyclooctyne $\mathbf{4 a}$, which is the product click-conjugated at the less azidophilic terminal alkyne moiety of diyne 1a (Fig. 1B). Herein, we demonstrate that further optimization of this protection method enables a facile preparation of a broad range of functional cycloalkynes, including proteins incorporated with a cycloalkyne moiety, from the corresponding functional azides.

We screened for conditions that efficiently afforded clickconjugated bicyclo[6.1.0]non-4-yne $(\mathrm{BCN})^{3 g}$ derivative $\mathbf{4 b}$ from diyne $\mathbf{1 b}$ and azide $\mathbf{2 a}$ (Table 1 ). The strained alkyne moiety of 1 b was protected by treatment with $(\mathrm{MeCN})_{4} \mathrm{CuBF}_{4}$ (2.2 equiv.) in $\mathrm{CH}_{2} \mathrm{Cl}_{2}$ via our previously reported method. ${ }^{5 h}$ The subsequent addition of azide 2a triggered CuAAC at the terminal alkyne 
Table 1 Screening of chelators

\begin{tabular}{|c|c|c|c|}
\hline & 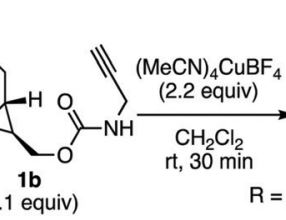 & $\begin{array}{c}\begin{array}{c}\mathrm{R}-\mathrm{N}_{3} 2 \mathrm{a} \\
(1 \text { equiv) } \\
\text { THPTA }\end{array} \\
\underset{(10 \mathrm{~mol} \%)}{\mathrm{rt}, 24 \mathrm{~h}}\end{array}$ & $\begin{array}{l}\text { Chelator } \\
\text { (80 equiv) } \\
\mathrm{rt}, 24 \mathrm{~h}\end{array}$ \\
\hline Entry & Chelator & & Yield of $\mathbf{4 b}$ from $\mathbf{1} \mathbf{b}^{a}(\%)$ \\
\hline 1 & $0.1 \mathrm{M}$ aq. EDTA.2Na & & Quant. $(98)^{b}$ \\
\hline $2^{c}$ & $0.1 \mathrm{M}$ aq. EDTA $2 \mathrm{Na}$ & & 93 \\
\hline 3 & $0.1 \mathrm{M}$ aq. NTA $2 \mathrm{Na}$ & & 41 \\
\hline 4 & $0.1 \mathrm{M}$ aq. DTPA $5 \mathrm{Na}$ & & Trace \\
\hline 5 & SiliaMetS thiourea & & $84^{b}$ \\
\hline 6 & SiliaMetS triamine & & 29 \\
\hline 7 & SiliaMetS imidazole & & 2 \\
\hline 8 & Resin(polystyrene)-PPh & ${ }_{2}(\mathrm{PS}-\mathrm{TPP})$ & $80^{b}$ \\
\hline
\end{tabular}

${ }^{a}$ Yields were determined by ${ }^{1} \mathrm{H}$ NMR analysis, unless otherwise noted. ${ }^{b}$ Isolated yields. ${ }^{c}$ TBTA was used instead of THPTA. EDTA.2Na = disodium ethylenediaminetetraacetate; NTA $2 \mathrm{Na}=$ disodium nitrilotriacetate; and DTPA. $5 \mathrm{Na}$ = pentasodium diethylenetriaminepentaacetate.

moiety because an excessive amount of copper was present in the reaction mixture. We found that using THPTA $^{10}$ instead of TBTA as a ligand to accelerate CuAAC was more favorable because it could be removed easily through an aqueous workup. We next explored reagents that could deprotect copper under milder conditions compared to those using highly nucleophilic aqueous ammonia. After extensive screening of chelating reagents, we found that aqueous EDTA.2Na (80 equiv.) efficiently removed copper to afford the desired $\mathbf{4 b}$ in an excellent yield in a one-pot three-step manner (Table 1, entry 1). In this sequence, TBTA was also available instead of THPTA for the CuAAC step (entry 2). In contrast, when NTA.2Na or DTPA. $5 \mathrm{Na}$ solution was used in the copper deprotection step, the yield of $\mathbf{3 b}$ drastically decreased (entries 3 and 4). Copper deprotection using a metal-scavenging reagent rendered the aqueous workup unnecessary. Among the examined chelating reagents immobilized onto silica-gel, SiliaMetS thiourea gave the best result (entry 5). Moreover, triphenylphosphine bound on polystyrene resin (PS-TPP) was also effective (entry 8). These aqueous workup-free methods were useful for preparing water-soluble cycloalkynes (vide infra).

The optimized conditions were applicable to the terminal alkyne-selective click reaction of a wide range of cycloalkynes bearing a terminal alkyne moiety, as demonstrated using azide 2a (Fig. 2). For example, dibenzo-fused cyclooctyne (DBCO) 4a, which we previously prepared, ${ }^{5 h}$ was uneventfully prepared from diyne 1a using aqueous EDTA.2Na instead of aqueous ammonia as the deprotecting reagent. Click-modified BCN derivative $\mathbf{4 c}$ bearing a bis(ethyleneoxy) linker was also prepared from diyne 1c quantitatively. The clickability of the strained alkyne moiety of diyne $\mathbf{1 d}$ with a cyclooctyne structure less strained compared to that of BCN was also protected using the cationic copper salt, and 1,4-triazole formation followed by removal of the copper salt proceeded smoothly to afford cyclooctyne 4d in high yield. This method enabled efficient preparation of click-conjugated dibenzo-fused azacyclooctyne (DIBAC) ${ }^{3 e} \mathbf{4 e}$ from DIBAC derivative $1 \mathrm{e}$ bearing a terminal alkyne moiety when the deprotection was performed

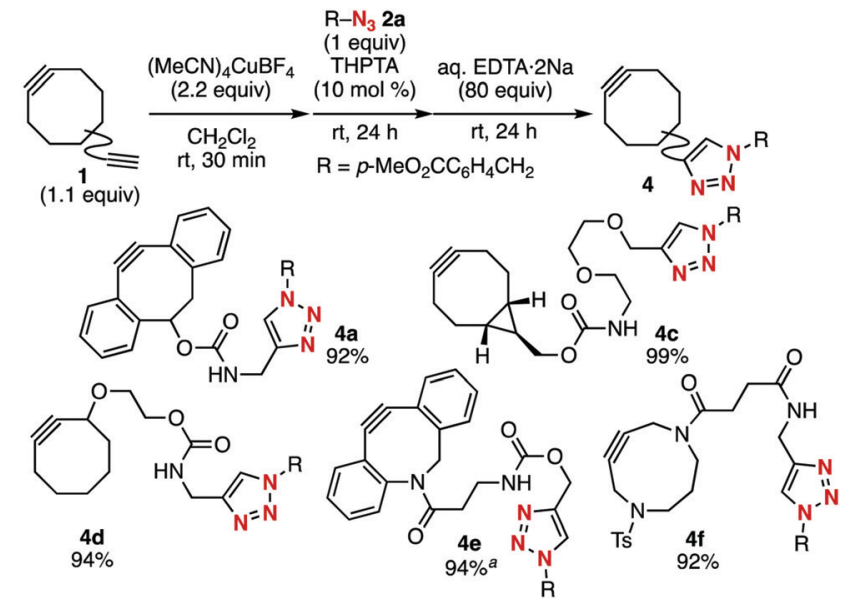

Fig. 2 Terminal alkyne-selective click conjugation of various diynes 1. ${ }^{a}$ PS-TPP (160 equiv.) was used instead of aq. EDTA.2Na.

using PS-TPP. ${ }^{11}$ Furthermore, not only eight-membered cycloalkynes but also nine-membered 4,8-diazacyclononyne (DACN) ${ }^{3 i}$ participated in this terminal alkyne-selective click reaction to afford DACN derivative 4 f from diyne $\mathbf{1 f}$.

Using this terminal alkyne-selective click conjugation method of diynes, we prepared cycloalkynes $\mathbf{4 g - 4 m}$ bearing a diverse range of functional groups from the corresponding functional azides $\mathbf{2 b}-\mathbf{2 h}$ without affecting the strained alkyne and functional moieties (Fig. 3). For example, BCN-HaloTag ligand $4 \mathbf{g}$ was efficiently prepared from azido-HaloTag ligand $2 \mathbf{b}^{5 c}$ and diyne 1b. The click conjugation of biotin with DACN derivative $\mathbf{1 f}$ bearing a terminal alkyne moiety proceeded smoothly to afford biotin-conjugated cycloalkyne $\mathbf{4 h}$ in high yield. Cycloalkyne $\mathbf{4 i}$, which includes a hydrophilic polyethylene moiety was also synthesized in good yield. Similarly, cycloalkynes $\mathbf{4 j - 4 m}$ conjugated with diverse fluorescent dyes such as coumarin 102, BODIPY, and tetraethylsulforhodamine were efficiently prepared from readily available fluorescent azides $\mathbf{2 e - 2 h}$.

Furthermore, Alexa Fluor 555 azide (2i), whose structure has not been disclosed by the suppliers but which is often used in biological experiments because of its favorable fluorescence characteristics, was transformed into the corresponding Alexa Fluor 555-DBCO 4n via this method (Fig. 4A). In this case, removal of the copper salt from the reaction mixture was efficiently achieved using PS-TPP; this process did not require an aqueous workup. Treatment of HEK293 cells expressing transmembrane domain-fused HaloTag protein on the cell surface with azido-HaloTag ligand $2 \mathbf{b}$ followed with $4 \mathbf{n}$ resulted in a successful cell surface-specific fluorescent labeling by SPAAC (Fig. 4B). ${ }^{12}$ This result clearly demonstrates the utility of the azideto-cycloalkyne switching technology.

Proteins incorporated with a cyclooctyne moiety, which were applicable to click modification with functional azides, were also easily prepared from azido-incorporated proteins, as demonstrated in the terminal alkyne-selective click conjugation using BCN-derived diyne 1c, thereby greatly expanding the utility of this method (Fig. 5A). For example, HaloTag protein-conjugated $\mathrm{BCN}$ was prepared from azido-HaloTag protein via the terminal 


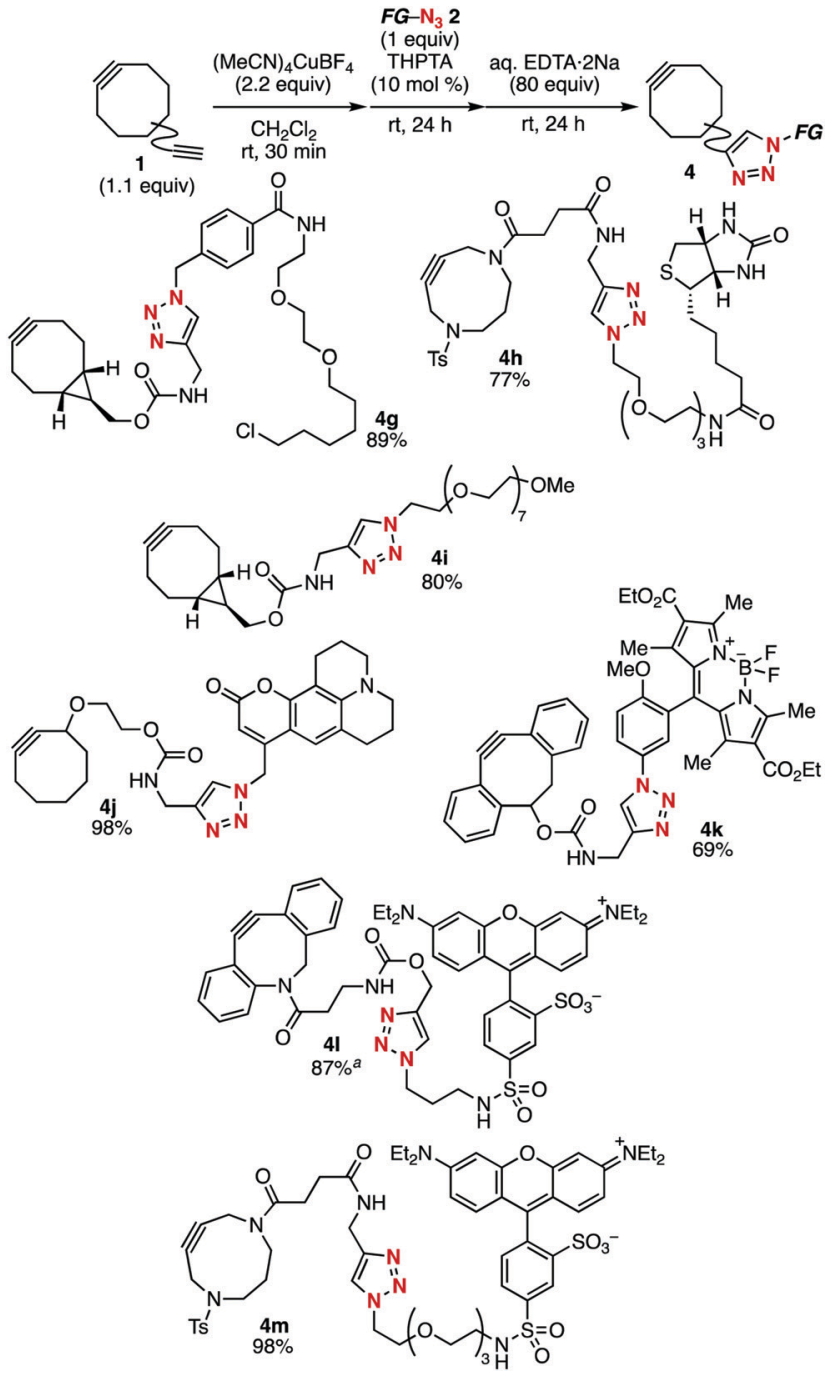

Fig. 3 Synthesis of various functional cycloalkynes from the corresponding azides. ${ }^{a}$ PS-TPP (160 equiv.) was used instead of aq. EDTA.2Na.

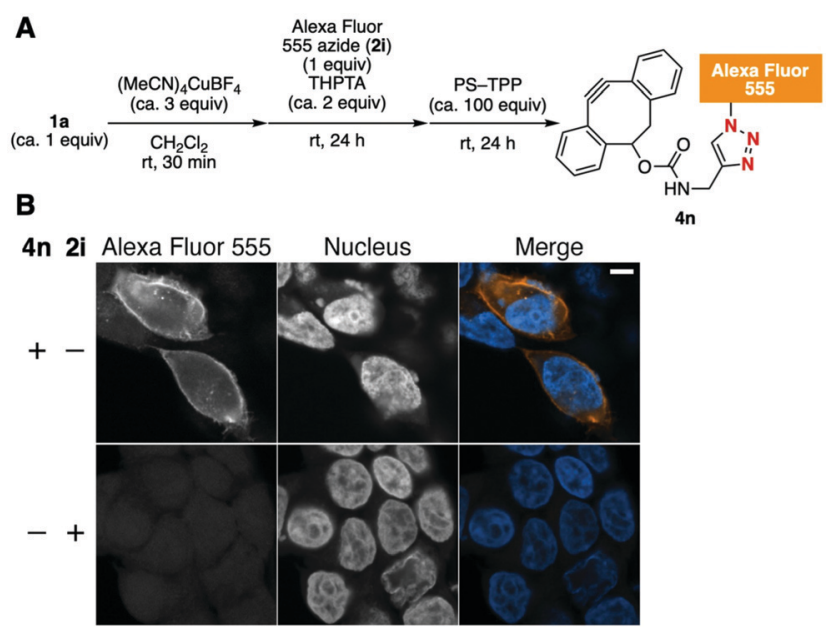

Fig. 4 (A) Synthesis of Alexa Fluor 555-DBCO 4n. (B) Fluorescent labeling of HaloTag protein on the cell surface with 4n. HEK293 cells expressing HaloTag on the surface were incubated with azido-HaloTag ligand $\mathbf{2 b}$, followed with $\mathbf{4 n}$ or $\mathbf{2 i}$. Scale bar, $5 \mu \mathrm{m}$. alkyne-selective CuAAC reaction of copper-protected 1c under slightly modified conditions, ${ }^{12}$ followed by removal of the copper salt upon treatment with an aqueous EDTA.2Na solution. The efficiency of the transformation was determined by further modification of the HaloTag protein-conjugated $\mathrm{BCN}$ via the SPAAC reaction using fluorescein azide $\mathbf{2 j}$. The SDS-PAGE analysis indicated that the desired fluorescein-labeled HaloTag protein was prepared in high efficiency, comparable to that prepared by the direct fluorescent labeling of HaloTag protein using fluorescein-HaloTag ligand 5 (Fig. 5B, lane 2 vs. lane 5).

Fluorescence modification of azido-incorporated cetuximab, an antibody against the human EGF receptor (EGFR), was also

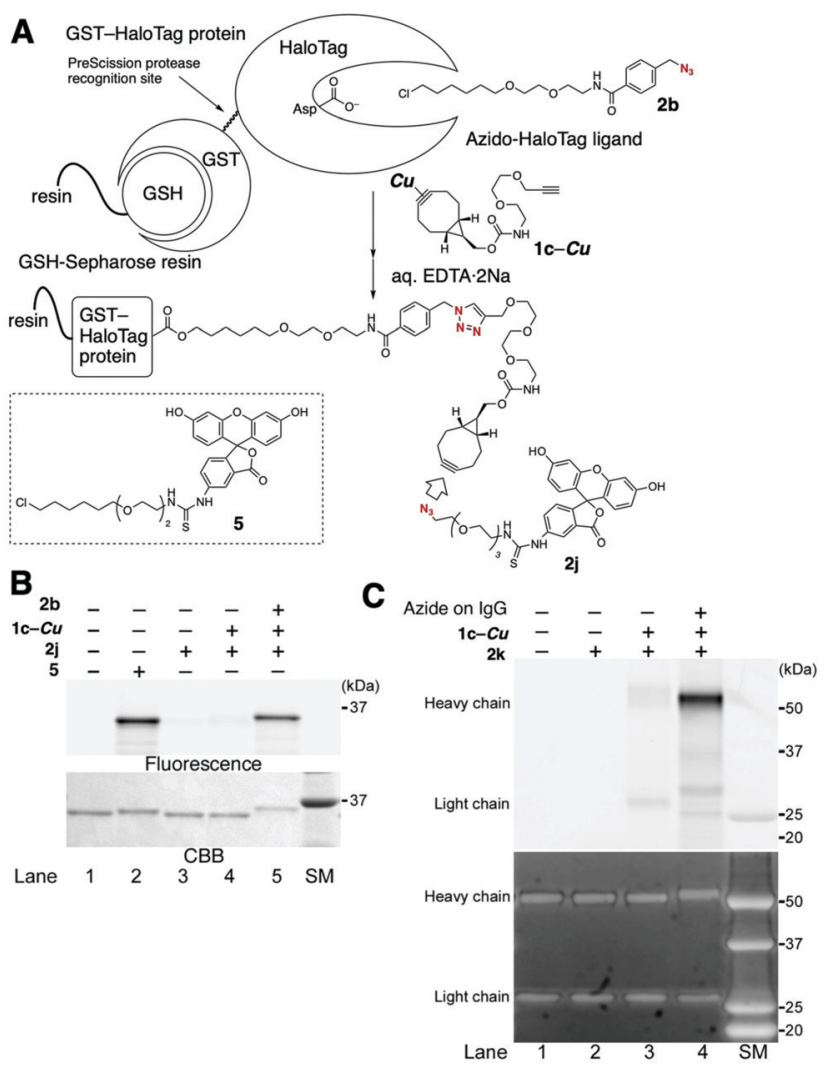

Fig. 5 Chemical modification of azido-incorporated proteins with a fluorescent azide via $\mathrm{BCN}$-conjugated proteins prepared by the terminal alkyne-selective click conjugation using $\mathrm{Cu}$-protected $\mathrm{BCN}$-derived diyne 1c-Cu. (A) Schematic illustration of the method. (B) Chemical modification of azido-HaloTag protein with fluorescein azide $\mathbf{2 j}$. GST-HaloTag protein bound on GSH-resin was incubated in the presence of fluorescein-HaloTag ligand $\mathbf{5}$ (lane 2 ) or in the presence $(+)$ or absence $(-)$ of azido-HaloTag ligand $\mathbf{2} \mathbf{b}$, copper-protected diyne $\mathbf{1} \mathbf{c}-\mathbf{C} \mathbf{u}$, and fluorescein azide $\mathbf{2} \mathbf{j}$ (lanes 3-5). The labeled GST-HaloTag proteins eluted from the resin were separated on SDS-PAGE. The gel was scanned using a fluorescence image analyzer and then stained with Coomassie brilliant blue (CBB). (C) Chemical modification of an azide-incorporated antibody with Alexa Fluor 488 azide (2k). An antibody installed with azido groups on its sugar chains was reacted with $\mathbf{1 c}-\mathbf{C u}$ in the presence of $\mathrm{CuSO}_{4}$, THPTA, and sodium ascorbate, followed by treatment with EDTA and Alexa Fluor 488 azide (2k). The labeled antibody was separated on SDS-PAGE, and the gel was scanned with a fluorescence image analyzer (upper panel) and then stained with One-step Ruby for the total protein detection (lower panel). SM indicates the size marker lane. 
achieved via a similar method (Fig. 5C). In this case, an azido group was enzymatically installed onto the sugar chain at the heavy chain of IgG. ${ }^{12}$ Treatment of the azido-antibody with copper-protected 1c followed by deprotection with EDTA-2Na solution afforded antibody-conjugated $\mathrm{BCN}$, which was efficiently labeled using Alexa Fluor 488 azide (2k) (Fig. 5C, lane 4). This result indicates that antibodies labeled with various functional groups are easily prepared from readily available functional azides using this system.

In summary, we have demonstrated that diverse functional cycloalkynes were easily prepared from functional azides by the terminal alkyne-selective CuAAC reaction with diynes bearing strained and alkyne moieties via transient protection of the former via complexation with copper. Chemical modification of azido-incorporated proteins with functional azides was efficiently achieved in this method. Further application studies using this method are ongoing.

This work was supported by AMED under Grant Numbers JP18am0101098 (Platform Project for Supporting Drug Discovery and Life Science Research, BINDS) and JP18am0301024 (the Basic Science and Platform Technology Program for Innovative Biological Medicine); JSPS KAKENHI Grant Numbers JP15H03118 and JP18H02104 (B; T. H.), JP16H01133 and JP18H04386 (Middle Molecular Strategy; T. H.), JP17H06414 (Organelle Zone; T. H.), JP26350971 (C; S. Y.), JP18H04568 (CMCB; I. K.), JP18J11113 (JSPS Research Fellow; T. M.), and JP17K13266 (Young Scientist B; Y. N.); the Cooperative Research Project of Research Center for Biomedical Engineering; and the Naito Foundation (S. Y.).

\section{Conflicts of interest}

There are no conflicts to declare.

\section{Notes and references}

1 (a) C. W. Tornøe, C. Christensen and M. Meldal, J. Org. Chem., 2002, 67, 3057; (b) V. V. Rostovtsev, L. G. Green, V. V. Fokin and K. B. Sharpless, Angew. Chem., Int. Ed., 2002, 41, 2596; (c) M. Meldal and C. W. Tornøe, Chem. Rev., 2008, 108, 2952; (d) J. E. Hein and V. V. Fokin, Chem. Soc. Rev., 2010, 39, 1302; (e) A. Mandoli, Molecules, 2016, 21, 1174.

2 (a) E. M. Sletten and C. R. Bertozzi, Angew. Chem., Int. Ed., 2009, 48, 6974; (b) M. F. Debets, C. W. J. van der Doelen, F. P. J. T. Rutjes and F. L. van Delft, ChemBioChem, 2010, 11, 1168; (c) J. C. Jewett and C. R. Bertozzi, Chem. Soc. Rev., 2010, 39, 1272; (d) J. Dommerholt, F. P. J. T. Rutjes and F. L. van Delft, Top. Curr. Chem., 2016, 374, 16; (e) E. G. Chupakhin and M. Y. Krasavin, Chem. Heterocycl. Compd., 2018, 54, 483.

3 (a) G. Wittig and A. Krebs, Chem. Ber., 1961, 94, 3260; (b) N. J. Agard, J. A. Prescher and C. R. Bertozzi, J. Am. Chem. Soc., 2004, 126, 15046; (c) S. T. Laughlin, J. M. Baskin, S. L. Amacher and C. R. Bertozzi, Science, 2008, 320, 664; (d) X. Ning, J. Guo, M. A. Wolfert and G.-J. Boons, Angew. Chem., Int. Ed., 2008, 47, 2253; (e) M. F. Debets, S. S. van Berkel, S. Schoffelen, F. P. J. T. Rutjes, J. C. M. van Hest and F. L. van Delft, Chem. Commun., 2010, 46, 97; $(f)$ J. C. Jewett, E. M. Sletten and C. R. Bertozzi, J. Am. Chem. Soc., 2010, 132, 3688; $(g)$ J. Dommerholt, S. Schmidt, R. Temming, L. J. A. Hendriks, F. P. J. T. Rutjes, J. C. M. van Hest, D. J. Lefeber, P. Friedl and F. L. van Delft, Angew. Chem., Int. Ed., 2010, 49, 9422; (h) A. Kuzmin, A. Poloukhtine, M. A. Wolfert and V. V. Popik, Bioconjugate Chem.,
2010, 21, 2076; (i) R. Ni, N. Mitsuda, T. Kashiwagi, K. Igawa and K. Tomooka, Angew. Chem., Int. Ed., 2015, 54, 1190; ( $j$ ) C. Gröst and T. Berg, Org. Biomol. Chem., 2015, 13, 3866; (k) K. Kaneda, R. Naruse and S. Yamamoto, Org. Lett., 2017, 19, 1096; (l) E. G. Burke, B. Gold, T. T. Hoang, R. T. Raines and J. M. Schomaker, J. Am. Chem. Soc., 2017, 139, 8029.

4 (a) H. C. Kolb, M. G. Finn and K. B. Sharpless, Angew. Chem., Int. Ed., 2001, 40, 2004; (b) D. M. Patterson and J. A. Prescher, Curr. Opin. Chem. Biol., 2015, 28, 141; (c) L.-H. Qin, W. Hu and Y.-Q. Long, Tetrahedron Lett., 2018, 59, 2214; (d) G. Liu, J. Hu and S. Liu, Chem. - Eur. J., 2018, 24, 16484.

5 For examples for selective conjugation using azides and/or alkynes as clickable groups, see: (a) V. Aucagne and D. A. Leigh, Org. Lett., 2006, 8, 4505; (b) P. M. E. Gramlich, S. Warncke, J. Gierlich and T. Carell, Angew. Chem., Int. Ed., 2008, 47, 3442; (c) I. Kii, A. Shiraishi, T. Hiramatsu, T. Matsushita, H. Uekusa, S. Yoshida, M. Yamamoto, A. Kudo, M. Hagiwara and T. Hosoya, Org. Biomol. Chem., 2010, 8, 4051; (d) H. Elamari, F. Meganem, J. Herscovici and C. Girard, Tetrahedron Lett., 2011, 52, 658; (e) S. Yoshida, A. Shiraishi, K. Kanno, T. Matsushita, K. Johmoto, H. Uekusa and T. Hosoya, Sci. Rep., 2011, 1, 82; $(f)$ P. A. Ledin, F. Friscourt, J. Guo and G.-J. Boons, Chem. - Eur. J., 2011, 17, 839; ( $g$ ) D. M. Beal, V. E. Albrow, G. Burslem, L. Hitchen, C. Fernandes, C. Lapthorn, L. R. Roberts, M. D. Selby and L. H. Jones, Org. Biomol. Chem., 2012, 10, 548; (h) S. Yoshida, Y. Hatakeyama, K. Johmoto, H. Uekusa and T. Hosoya, J. Am. Chem. Soc., 2014, 136, 13590; (i) D. N. Barsoum, N. Okashah, X. Zhang and L. Zhu, J. Org. Chem., 2015, 80, 9542; $(j)$ P. Gobbo, T. Romagnoli, S. M. Barbon, J. T. Price, J. Keir, J. B. Gilroy and M. S. Workentin, Chem. Commun., 2015, 51, 6647; (k) A. Maruani, M. E. B. Smith, E. Miranda, K. A. Chester, V. Chudasama and S. Caddick, Nat. Commun., 2015, 6, 6645; (l) R. R. Ramsubhag and G. B. Dudley, Org. Biomol. Chem., 2016, 14, 5028; (m) D. A. Sutton, S.-H. Yu, R. Steet and V. V. Popik, Chem. Commun., 2016, 52, 553; (n) M. Z. C. Hatit, J. C. Sadler, L. A. McLean, B. C. Whitehurst, C. P. Seath, L. D. Humphreys, R. J. Young, A. J. B. Watson and G. A. Burley, Org. Lett., 2016, 18, 1694; (o) S. Yoshida, K. Kanno, I. Kii, Y. Misawa, M. Hagiwara and T. Hosoya, Chem. Commun., 2018, 54, 3705; (p) T. Meguro, S. Yoshida, K. Igawa, K. Tomooka and T. Hosoya, Org. Lett., 2018, 20, 4126; (q) S. Yoshida, J. Tanaka, Y. Nishiyama, Y. Hazama, T. Matsushita and T. Hosoya, Chem. Commun., 2018, 54, 13499; $(r)$ T. Yokoi, H. Tanimoto, T. Ueda, T. Morimoto and K. Kakiuchi, J. Org. Chem., 2018, 83, 12103; $(s)$ D. Svatunek, N. Houszka, T. A. Hamlin, F. M. Bickelhaupt and H. Mikula, Chem. - Eur. J., 2019, 25, 754; $(t)$ T. Yokoi, T. Ueda, H. Tanimoto, T. Morimoto and K. Kakiuchi, Chem. Commun., 2019, 55, 1891.

6 For examples for selective conjugation using functional groups other than azides or alkynes, see: (a) B. C. Sanders, F. Friscourt, P. A. Ledin, N. E. Mbua, S. Arumugam, J. Guo, T. Boltje, V. V. Popik and G.-J. Boons, J. Am. Chem. Soc., 2011, 133, 949; (b) M. R. Karver, R. Weissleder and S. A. Hilderbrand, Angew. Chem., Int. Ed., 2012, 51, 920; (c) D. N. Kamber, L. A. Nazarova, Y. Liang, S. A. Lopez, D. M. Patterson, H.-W. Shih, K. N. Houk and J. A. Prescher, J. Am. Chem. Soc., 2013, 135, 13680; (d) M. K. Narayanam, Y. Liang, K. N. Houk and J. M. Murphy, Chem. Sci., 2016, 7, 1257; (e) T. Meguro, S. Yoshida and T. Hosoya, Chem. Lett., 2017, 46, 1137; $(f)$ T. Meguro, N. Terashima, H. Ito, Y. Koike, I. Kii, S. Yoshida and T. Hosoya, Chem. Commun., 2018, 54, 7904.

7 (a) J. Lahann, Click Chemistry for Biotechnology and Materials Science, John Wiley \& Sons, West Sussex, 2009; (b) W. Xi, T. F. Scott, C. J. Kloxin and C. N. Bowman, Adv. Funct. Mater., 2014, 24, 2572.

8 (a) C. Wentrup, Acc. Chem. Res., 2011, 44, 393; (b) D. Intrieri, P. Zardi, A. Caselli and E. Gallo, Chem. Commun., 2014, 50, 11440.

9 (a) P. Thirumurugan, D. Matosiuk and K. Jozwiak, Chem. Rev., 2013, 113, 4905; (b) C. S. McKay and M. G. Finn, Chem. Biol., 2014, 21, 1075.

$10(a)$ T. R. Chan, R. Hilgraf, K. B. Sharpless and V. V. Fokin, Org. Lett., 2004, 6, 2853; (b) X.-M. Liu, A. Thakur and D. Wang, Biomacromolecules, 2007, 8, 2653.

11 When the deprotection was performed using aq. EDTA.2Na, click conjugated DIBAC $4 \mathbf{e}$ was obtained in low yield $(27 \%)$ due to the slow deprotection.

12 See the ESI $\dagger$ for details. 